\title{
O Brasil na Grande Guerra: contornos de uma política nacional de censura (1917-1918)
}

Fecha de recepción: 5/8/2021 Fecha de aprobación: 27/9/2021

\section{Resumo}

Durante a Grande Guerra, e tal como outros países considerados "periféricos", o Brasil teve seu lugar no palco das nações que em alguma medida foram mobilizadas, embora sua participação no front tenha sido limitada. Nesse sentido, a partir de uma abordagem transnacional, estamos interessados em refletir sobre aspectos que, até ao momento, permaneceram pouco analisados ou negligenciados pela historiografia que se debruça sobre a I Guerra Mundial no país. Propomo-nos, então, neste artigo, mapear e analisar as estruturas múltiplas de censura instauradas no território brasileiro durante o conflito, e que se relacionam com a difusão de propaganda de guerra no país, sobretudo a partir de 1917.

Palavras-chave: Primeira Guerra Mundial, Brasil, Propaganda, Censura

\section{Brasil en la Gran Guerra: contornos de una política nacional de censura (1917-1918)}

\section{Resumen}

Este artículo analiza el múltiple sistema de censura establecido en Brasil en el transcurso de la Primera Guerra Mundial, principalmente a partir de 1917. Entre los años 1914 y 1918, Brasil estuvo en cierta medida movilizado, así como otros países del mundo "periférico", aunque su participación en el frente 
haya sido limitada. En este sentido, a partir de un abordaje transnacional, buscamos reflexionar sobre aspectos del conflicto que, hasta el momento, no han sido planteados con profundidad por la historiografía de la Gran Guerra, sobre todo acerca del impacto político y cultural de la censura en el país.

Palabras clave: Primera Guerra Mundial, Brasil, Propaganda, Censura

\title{
Brazil in the Great War: Outlining a national policy censorship (1917-1918)
}

\begin{abstract}
This article analyses the diversified censorship system established in Brazil during the First World War, which was vital to the circulation of war propaganda, mainly from 1917. Between 1914-1918, Brazil was somehow mobilized, like other countries from the "peripheric" world, although its participation at the front was not expressive. Based on a transnational approach, we seek to reflect upon aspects of the conflict that, so far, have been neglected by the historiography of the Great War, namely the cultural and political impact of censorship in the country.
\end{abstract}

Keywords: First World War, Brazil, Propaganda, Censorship

Durante a I Guerra Mundial, e tal como outros países considerados "periféricos", o Brasil teve seu lugar no palco das nações que em alguma medida foram mobilizadas, embora sua participação nos campos de batalha tenha sido limitada. 0 fenômeno de totalização da guerra, isto é, o desenvolvimento de uma lógica de captação de recursos e integração de setores sem precedentes, significa que cada sociedade se adequou de forma única à realidade do conflito, tivessem elas enviado homens para o teatro da guerra ou não, como foi o caso brasileiro. Tal abordagem está em sintonia com uma renovada história da Grande Guerra que amplia o enfoque de análise e considera o conflito para além dos limites e da cronologia consagrados, que tem como referência o front ocidental (cf. Compagnon et al., 2018), tendendo a escrever a história da guerra em termos transeuropeus e transatlânticos (Winter, 2014a: 6-9).

Nesse sentido, a partir de uma perspectiva transnacional, estamos interessados em refletir sobre aspectos que, até o momento, permaneceram pouco analisados ou negligenciados pela historiografia que se debruça sobre a I Guerra Mundial no território brasileiro, buscando redimensionar o lugar ocupado pelo Brasil no âmbito da história global do conflito. Propomo-nos, então, neste artigo mapear e analisar as múltiplas estruturas de censura instauradas no país durante o conflito - a saber, a da imprensa, telegráfica, postal 
e telefônica -, que se relacionam com a difusão nacional de propaganda de guerra, sobretudo a partir de 1917.

\section{Uma guerra para além das trincheiras}

Ao refletirem sobre violência e consentimento das sociedades durante a Grande Guerra, Annette Becker e Stéphane Audoin-Rouzeau consideram o seu profundo impacto por ter legado ao século XX a "guerra total", um novo modelo de conflito que se apresentaria de forma mais completa com a II Guerra Mundial. Embora enfoquem na experiência europeia, os historiadores franceses identificam um eixo que é central para a reflexão que propomos neste trabalho: a necessidade de refletir de forma concomitante sobre o processo de mundialização e o de totalização da guerra. Totalização na medida em que o confronto foi muito além da linha da frente; houve um progresso da mobilização tanto econômica quanto cultural das frentes internas, assim como do poder de fogo, da propagação do conflito e do bloqueio estratégico que surgiu no fim de 1914. Para os autores, "o processo de totalização da guerra está profundamente ligado a uma transposição de limiares, de graus de violência do confronto, transposição que tem sua origem nos sistemas de representação das sociedades envolvidas na imensa provação" (AudoinRouzeau y Becker, 1998: 242). Já a mundialização se refere à entrada dos Estados Unidos no conflito em 1917 e ao papel que os territórios coloniais desempenharam nele, transformando-o em uma guerra mundial em defesa de uma cultura europeia (240-256).

É nesse contexto que o Brasil tem seu lugar no palco das nações que de alguma forma foram mobilizadas. Sua participação no conflito foi limitada; o país enviou uma missão médico-militar à França, nove oficiais aviadores do Exército e da Marinha para auxiliar nos combates aéreos, e uma Divisão Naval, que foi vítima da pandemia de gripe espanhola na costa da África. No entanto, como mencionado, procuraremos nas próximas páginas delinear tanto conexões com os países Aliados como a estrutura de censura que se estabeleceu no país, que, dentre seus desdobramentos possíveis, estão conectadas à narrativa (ou narrativas) sobre o conflito elaborada no Brasil.

A propaganda de guerra está intrinsicamente vinculada a esse procedimento porque a supressão de fontes de informações permite o modelamento do conteúdo da propaganda que, em última instância, objetivava garantir o apoio nacional. Os Estados beligerantes estavam, sobretudo, atentos ao potencial

1 É necessário, no entanto, tomar em conta os diversos usos que o conceito de "guerra total" teve ao longo das décadas, respondendo a agendas específicas. A ideia está originalmente vinculada à narrativa dominante da história militar moderna, informando histórias de combate como a Revolução Francesa e a Guerra Civil Americana, e se relaciona com premissas filosóficas de origem alemã. Dentre elas está a noção de "guerra absoluta", de Carl von Clausewitz, o tipo-ideal weberiano e a de "Der totale Krieg", de Erich Ludendorff. Estamos interessados aqui em seu uso como perspectiva teórica para a análise do fenômeno da I Guerra Mundial no Brasil, nos termos propostos por John Horne (1997). 
da imprensa enquanto instrumento de propaganda, um espaço onde poderiam ser angariadas causas específicas, propagar ideias nacionalistas, e servir como um agente do status quo. No entanto, como mostram pesquisas sobre o impacto da propaganda na opinião pública durante a I Guerra Mundial (Horne, 1997 y 2010; Welch, 2003; Paddock, 2014; Robertson, 2014; Pennell, 2014; Djebabla, 2014; Steuer, 2014), ainda que a propaganda e a censura fossem utilizadas no sentido de se alcançar um maior efeito sobre a narrativa da guerra - isto é, a sua elaboração de sentido —, a forma como as populações concebiam e se posicionavam em relação ao conflito tinha uma ligação mais próxima com um processo de consentimento, negociação e desejo, e não tanto de manipulação e coerção estatal, como bem nos lembra Jay Winter:

Dominação estatal não significa direcionamento estatal. Sim, havia manipulação vinda de cima, mas isso está longe de ser o fim da história. Uma das características-chave da propaganda é o seu caráter dual. Ela mistura polêmica política com apelos que se originam no setor privado. O poder da propaganda de estado era uma função de sua relação sinergética com a opinião vinda de baixo (1998: 217). ${ }^{2}$

No Brasil, assim como na América Latina de forma geral, essa propaganda se traduziu em conteúdos, imagens, símbolos e elaborações que tinham a imprensa como seu principal veiculador, embora não tenha sido o único. Contudo, foi sobretudo através dos jornais que milhões de latino-americanos tiveram contato com os desdobramentos da guerra, particularmente os que ocorriam no continente europeu. Deve-se salientar, no entanto, que ainda não existem estudos aprofundados sobre o tema particularmente no Brasil; ${ }^{3}$ no caso da América Latina de forma mais ampla, existem trabalhos que, com variados graus, se debruçam a respeito da propaganda de guerra que circulou na região. ${ }^{4}$

A veiculação de notícias no período se apoiou em um sistema de cabeamento e telegrafia que remontava ao século XIX e que era desde então comandado por um cartel de agências informativas: a francesa Havas (1832), a britânica Reuters (1851), a alemã Wolff (1849) e, mais tarde, a norte-americana Associated Press (1846), empresas que passaram a "dividir" o mundo em áreas de influência para a coleta e distribuição de notícias.

2 De forma análoga, Emily S. Rosenberg sustenta que, "[...] tal como aconteceu com as campanhas de informação da I Guerra Mundial [nos Estados Unidos], novas burocracias, tecnologias e técnicas foram combinadas para que fossem criadas formas mais energéticas de censura doméstica e vigilância. Tal coerção não consistia na oposição à persuasão, mas em seu complemento" (2010: 55).

3 Sidney Garambone (2003) traça o posicionamento da imprensa fluminense durante o conflito no escopo das relações internacionais e a repercussão da guerra ao analisar os jornais Correio da Manhã e $O$ Jornal do Commercio. A obra O Adeus à Europa..., de Olivier Compagnon (2014), por sua vez, embora tenha uma perspectiva mais abrangente a respeito de diversas dimensões da guerra no Brasil e na Argentina, se detém em alguma medida no tema das representações do conflito na imprensa brasileira.

$4 \mathrm{O}$ artigo de Stefan Rinke (2015), publicado no International Encyclopedia of the First World War, dá um panorama sobre a propaganda da I Guerra Mundial na América Latina; já o seu livro Latin America and the First World War (2017) perpassa este tema e outros a partir de uma perspectiva global do conflito no subcontinente. Destacamos ainda a obra La trinchera austral. La sociedad argentina ante la Primera Guerra Mundial (2017), de María Inés Tato, que explora as repercussões do conflito no sentido transnacional e da história cultural na sociedade argentina. 
Com efeito, a disseminação de notícias advindas da Europa por meio de telégrafos era feita por este cartel de agências internacionais; a Reuters tinha alcance na América do Sul, e a Havas era principal agência na América Latina e grande fornecedora da imprensa fluminense (Enders y Compagnon, 2004; Molina, 2015). A partir da tentativa de controle dos meios de comunicação entre a Europa e a América Latina foi possível criar um discurso dominante que legitimava a conflagração do conflito. ${ }^{5}$ Os jornais e revistas ilustradas tiveram, desse modo, um papel fundamental ao permitir que discursos a respeito do conflito chegassem tanto a um público letrado quanto aos que consumiam narrativas mais visuais:

\footnotetext{
Em um momento em que se deu a profissionalização do literato em jornalista, essa intelectualidade se mostrou uma figura poderosa, emergindo como agente social diferenciado ao cristalizar e difundir as representações da guerra. Foram eles os mediadores culturais do conflito para os brasileiros, que imaginavam a Grande Guerra a partir de seus comentários, dos informes da imprensa por meio de agências internacionais, e de fotografias. De fato, tais publicações atingiam e transformavam os hábitos também das camadas populares, apesar de serem endereçadas às elites. Em um contexto de alto analfabetismo, esses leitores foram expostos a imagens publicitárias, desenhos, mapas, cartazes e estandartes, frutos de uma - "pedagogia urbana moderna" (Arouca, 2018: 2).
}

Os Estados Unidos, por sua vez, conquistaram espaço midiático a partir de 1917, quando se tornaram beligerantes, possibilitando a instauração de sua política de propaganda de forma mais eficiente ao redor do mundo em consonância com as agências de notícias de seu país: a Associated Press e a United Press. Além disso, a partir da criação do Committee on Public Information (CPI) - o departamento oficial de propaganda do país - enviou para diversos países, inclusive o Brasil, filmes, litografias e fotografias para veicular a justificativa de sua participação na guerra, bem como disseminar valores norte-americanos de forma mais ampla (cf. Complete Report of the Chairman of the Committee on Public Information..., 1920). ${ }^{6}$

É importante ressaltar que, até o momento, não foi feita uma investigação sistemática sobre a propaganda e censura brasileira durante a I Guerra Mundial. Alguns trabalhos mencionam sua existência sem, contudo, se debruçarem com profundidade sobre essa lacuna historiográfica. Nesse sentido, podemos citar as pesquisas de Frederick Luebke (1987), Francisco Vinhosa (1990), Olivier Compagnon (2014), Antonio Gasparetto Júnior (2018) e Cristiano de Brum (2018). Ao analisar os Boletins Semanais de Júlio Mesquita publicados no jornal $O$ Estado de S. Paulo, Carlos Roberto Almeida (2017) se atenta à

5 A propaganda aliada no exterior não se limitava, no entanto, à censura dos telegramas. A circulação de panfletos, livros e revistas ilustradas como O Espelho (enviada para o Brasil e Portugal) e America Latina (destinada aos países de língua espanhola) são exemplos do esforço para fixar um imaginário favorável aos Aliados na América Latina (Sanders y Taylor, 1982: 120).

6 O escopo deste artigo não permite nos aprofundarmos sobre os projetos dos Aliados no Brasil de forma específica, e na América Latina de forma geral, no entanto, vale destacar que o trabalho do CPI foi contundente na região, assim como os Estados Unidos tiveram uma política particular de auxílio na censura brasileira entre 1917 e 1918, análoga às iniciativas da Grã-Bretanha. 
censura francesa e não à brasileira, apesar de reconhecê-la, tendo em vista que a imprensa daquele país era a principal fonte sobre o front europeu para os escritos do jornalista paulista.

Com nossa pesquisa em andamento, buscamos contribuir com a análise e caracterização de uma prática que esteve em vigor durante mais de um ano e mobilizou diversas esferas da administração estatal, bem como teve o apoio direto de países beligerantes, como foi o caso da Grã-Bretanha e dos Estados Unidos. Mais especificamente, interessa-nos compreender como esse sistema se relacionava com o conteúdo que era veiculado pela imprensa - um canal primordial de difusão e ideias -, porém não só, uma vez que ele atingiu diversas esferas estatais. Desse modo, para além das decisões cotidianas relativas ao funcionamento da censura e, em última análise, da propaganda, identificar sua estrutura e a ação de seus agentes nesse processo é uma etapa fundamental para compreendermos como o controle da circulação de notícias pôde se desenvolver durante a Grande Guerra no Brasil.

\section{Contornos oficiais de censura no Brasil}

Embora possamos identificar uma prática transnacional de censura durante a I Guerra Mundial, ${ }^{7}$ nos parece igualmente importante ter em mente que ela se configurou de forma contextual; cada estado beligerante respondeu à sua maneira à medida, que seria aplicada de acordo com sua situação nacional e internacional. Como Robert Darnton enfatiza sobre a execução da censura em diferentes países, "uma pessoa chamada de censor pode se comportar conforme as regras de um jogo que são incompatíveis com aquelas seguidas por outra pessoa, considerada um censor em outro sistema. Os jogos em si são diferentes" (2016). Nesse sentido, é válido não reduzir a censura a algo rígido, uma entidade à parte absolutamente normativa. Ela foi um processo complexo, que permeou instituições, mobilizou indivíduos e acionou interpretações diversas.

Por definição, a ideia de censura perpassa uma lógica de supressão de informações. De forma mais precisa, conforme a pesquisadora Beate Müller, ela pode ser delimitada como "um controle autoritário sobre o que atinge a esfera pública por outra pessoa que não o expedidor e o destinatário pretendido da mensagem", operando "com base na regulação oficial (se não legislação), institucionalização, e administração dos procedimentos de controle em vigor" (2004: 12-13). ${ }^{8}$

7 Para Jay Winter, a história transnacional é intrinsicamente global, e "não começa em um estado e se move para outros, mas lida com múltiplos níveis de experiência histórica como dados, níveis que estão abaixo e acima do nível nacional" (2014b: 20). Desse modo, o empreendimento de uma história global da Grande Guerra implica ir muito além das trincheiras, incorporando dimensões econômicas, sociais, políticas e culturais (Rinke, 2017: 9).

8 E a historiadora continua: "A vigilância da censura sobre a conformidade das normas - sejam elas de natureza legal, estética ou amplamente ideológica - inevitavelmente requer estruturas autoritárias, ao 
A censura relativa a um período de guerra traz à tona aspectos mais específicos relativos à sua concepção e aplicação. No que se refere à I Guerra Mundial, com a deflagração do conflito passou a haver uma disputa no campo discursivo entre os beligerantes para justificar sua entrada na guerra em consonância com as leis internacionais. Desse modo, existiu desde o início uma mobilização dos discursos culturais, do ponto de vista ideológico, para legitimar o grande esforço de guerra para a população civil. Nesses termos, a propaganda de estado e a censura eram consideradas justificadas em prol do interesse em se veicular a "verdade" sobre o que ocorria no front (Rasmussen, 2010: 315).

No Brasil, durante o período de neutralidade, esse confronto de narrativas pôde ocorrer por meio do controle do fluxo de informações que chegavam da Europa pelos Aliados, possibilitando que esse conteúdo fosse reelaborado por aqueles que apoiavam a sua causa. Ainda assim, outras vozes, mais alinhadas aos Impérios Centrais, ${ }^{9}$ também se fizeram ouvir no país, gerando uma produção discursiva e simbólica que não pode ser ignorada. ${ }^{10}$ Para além disso, embora em desvantagem, a propaganda alemã também se fez presente e foi expressiva na América Latina. ${ }^{11}$

O caminho para a beligerância foi progressivo e tensionado por ataques a navios brasileiros pela Alemanha, porém abrangeu ainda outras dimensões da política interna brasileira, tais como a saída de Lauro Müller da chancelaria, dando lugar a Nilo Peçanha; a entrada dos Estados Unidos na guerra, em abril de 1917, e a perspectiva do novo sistema de relações internacionais que se delinearia no pós-guerra, materializado com a eventual assinatura do Tratado de Versalhes e a criação da Liga das Nações. Além disso, a declaração do estado de guerra se confundia com a tentativa de controlar tensões internas que despontavam há tempos no país. 0 aumento do custo de vida e a inflação de gêneros de necessidade básica, diretamente relacionados ao contexto econômico internacional, explicam, parcialmente, a deflagração da greve geral em julho de 1917 por sindicados de orientação anarquista em São Paulo, ${ }^{12}$ onde 40 mil trabalhadores paralisaram suas atividades (McGee Deutsch, 1999: 111; Daróz, 2016: 108; Compagnon, 2014: 135-137).

menos hierárquicas, para fins de monitoramento, que pode ser realizado com muito mais facilidade se as etapas da censura forem documentadas" (Müller 2004: 13).

9 Configura-se como Aliados, ou Tríplice Entente, o Reino Unido, França e Império Russo, e como Impérios Centrais - a camada Tríplice Aliança - Alemanha, Império Austro-húngaro, à qual se juntariam o Império Otomano e Bulgária.

10 Como foi o caso, por exemplo, do deputado Dunshee de Abranches (1915) e do jornalista Mario Pinto Serva.

11 No Brasil, circularam materiais produzidos na Alemanha, tais como a importante revista de fotografia Der Große Krieg in Bildern e edições traduzidas do jornal Hamburger Nachrichten. Do ponto de vista historiográfico, podemos ainda mencionar o trabalho de María Inés Tato (2014), que dá um panorama sobre a propaganda alemã na Argentina.

12 Existe um debate historiográfico em torno das causas que levaram à eclosão do episódio. Christina Lopreato (1996), por exemplo, relativiza o seu caráter espontâneo, que Boris Fausto (1977) havia apontado anteriormente, e revela a agência dos militantes que participavam do movimento. Luigi Biondi (2009), por sua vez, afirma que a greve se deveu a múltiplos fatores, a saber, a combinação da pressão econômica do período bem como as ações articuladas dos indivíduos que participaram desse processo (cf. Dos Santos, 2016: 142). 
Logo, com a formalização da beligerância em outubro de 1917, o Estado brasileiro instaurou oficialmente a censura no país como forma de, em última análise, se proteger do inimigo estrangeiro. Essa prerrogativa parece ter sido uma interpretação da Constituição de 1891 que, de forma implícita, poderia justificar o procedimento com o intuito de salvaguardar a integridade nacional, embora entrasse em conflito com o artigo que assegurava a "inviolabilidade dos direitos concernentes á liberdade, á segurança individual e á propriedade" (Constituição da República dos Estados Unidos do Brasil, 1891).

No que se refere especificamente à modalidade de censura na imprensa, as primeiras instruções oficiais do Governo Brasileiro relativas à fiscalização foram anunciadas a 27 de outubro de 1917, um dia após a entrada do país na guerra. Dentre as deliberações estabelecidas no Palácio do Catete, ficou decidido pela proibição de publicação tanto de jornais em língua alemã quanto de "boatos alarmantes e notícias de caráter militar" em periódicos no geral. Foram estabelecidas 14 proibições oficiais para publicação, que foram levadas ao conhecimento dos jornais pelos censores.

O Ministério das Relações Exteriores decidiu que tanto os jornais quanto o serviço telegráfico seriam fiscalizados (Anais da Câmara dos Deputados, 11 de agosto de 1918: 2208); a responsabilidade da aplicação deste último caberia ao Itamaraty e a dos primeiros ao Ministério da Justiça e Negócios Interiores (Relatórios apresentado ao Presidente da Republica dos Estados Unidos do Brasil pelo Ministro da Justiça e Negócios Interiores Dr. Carlos Maximiliano Pereira dos Santos dos anos de 1917 e 1918, 1918). No entanto, na prática, os dois Ministérios teriam funções relacionáveis, tendo em vista que o telégrafo brasileiro, fixado em uma rede submarina de cabeamento, seria o intermediário entre informações vindas da Europa ou dos Estados Unidos e os censores da imprensa brasileira, que estariam sob responsabilidade do Ministério da Justiça. Desse modo, não seria possível dissociar os dois setores da administração, cujo trabalho era executado de forma integrada do ponto de vista internacional. A esse esforço seria também vinculado o Ministério da Viação e Obras Públicas, que administrava o telégrafo (Relatórios apresentado ao Presidente da Republica dos Estados Unidos do Brasil..., 1918), o serviço telefônico, a radiotelegrafia e os correios do país, o que permitia delinear em alguma medida um procedimento de censura nacional em diversas instâncias, embora cada região tivesse suas especificidades em termos de aplicação.

Não obstante ainda fossem necessárias reuniões futuras para decidir detalhes sobre a censura específica dos jornais, ficou estabelecido naquele primeiro momento que a medida visaria unicamente as notícias de caráter militar e internacional, que só poderiam ser divulgadas se emanassem do governo pelos órgãos respectivos. Logo, foi informado que qualquer outro conteúdo que não fosse daquela natureza poderia ser transmitido aos jornais sem risco de corte. Outra determinação foi a de que os telegramas para os 
estados ou para o exterior só poderiam transmitir notícias oficiais fornecidas à imprensa pelo governo. Para o então Ministro das Relações Exteriores, Nilo Peçanha, se tratava "de um simples dever patriótico e os jornais serão os primeiros nesse momento angustioso do país a evitar divulgação de boatos ou notícias alarmantes" (Instruções aos correspondentes dos jornaes, 1917). Em pronunciamento, o Presidente Venceslau Brás, esperava "da imprensa, que nunca faltou com o seu patriotismo nos momentos graves, se dispensar discussões inorportunnas" (O Brasil em guerra, 1917) para garantir a unidade na nação frente ao agressor. Em tese, a censura era compreendida como uma medida de policiamento interno e eminentemente nacional, que não poderia proteger pessoas particulares contra injúria ou difamação, mas apenas os representantes diplomáticos. Desse modo, comentários críticos em relação ao Presidente da República e seus Ministros seriam permitidos (Ofício do Ministério da Justiça e Negócios Interiores ao Itamaraty, 17 de setembro de 1918).

Ainda no fim de outubro, o Ministro da Justiça e Negócios Interiores, Carlos Maximiliano, anunciou aos governadores e presidentes dos estados da federação que a censura dos jornais da capital seria feita por funcionários civis do Ministério da Justiça. A decisão buscava desvincular a prática da polícia, por tê-la aplicado durante o estado de sítio anterior, a fim de tirar dessa medida de segurança pública qualquer caráter de coação (A censura na imprensa, 1917). A imprensa julgou as instruções recebidas oficialmente pelos censores na capital como precisas e uniformes, consideradas até mesmo brandas, mas foram interpretadas de forma diversa e contraditória pelos funcionários do governo (Gazeta de Notícias, 1917).

Para os veículos da imprensa e políticos, o estado de sítio de 1914 foi um ponto de referência para julgar a censura aplicada durante a I Guerra Mundial. A polícia delegava naquele período a missão de reprimir a liberdade de imprensa ao critério seletivo da função de censor. 0 jornal carioca $O$ Paiz, por exemplo, concordava com a necessidade de censura em 1917, uma vez que o jornalista não julga se a notícia que escreve é ou não conveniente, mas interessa que fosse feita por pessoas capazes de efetuá-la com critério (Censura de imprensa, 1917). 0 mesmo foi constatado pelo Gazeta de Notícias (1917).

O oposicionista Correio da Manhã, por sua vez, solicitava o desenvolvimento de uma norma de ação conjunta entre censores e periódicos. Sua crítica não era direcionada aos funcionários incumbidos pelo Ministro do Interior de fiscalizar a imprensa, pois eram "muito gentis" e nada tinham a ver com os "delegadinhos de última hora" que o governo encaminhava para os jornais em 1914 "com o fim de não consentirem que se falasse nos tristes sucessos do sítio de outros meses" (1917). Podemos constatar, de forma geral, que nessas primeiras semanas os jornais da capital concordavam com a justificativa de cerceamento, diferentemente do estado de sítio anterior, porém não tanto com os critérios pelos quais a censura vinha sendo aplicada. 


\section{Censura em debate}

A formulação e aplicação da censura durante o estado de beligerância brasileiro em 1917 não pode ser descolado da instauração poucas semanas depois do estado de exceção. Muitas foram as formas e designações daquilo que no Brasil se consagra como estado de sítio; as nações beligerantes europeias o colocaram em vigor a partir de 1914, porém detendo especificidades. ${ }^{13}$ No território brasileiro, o sítio ajudou a sedimentar as configurações da estrutura políticoinstitucional da Primeira República, isto é, serviu como um instrumento de hegemonia de poder do Estado e de consolidação do regime republicano nas mãos das elites. Entretanto, como salientado por José Murilo de Carvalho, a interpretação conservadora dada à Carta de 1891, aplicada em consonância com o situacionismo oligárquico, fez despontar a frustração e impotência entre os liberais, que tentaram, em vão, sucessivamente reformá-la a fim de efetivar a República idealizada (Carvalho, 1990: 32-33).

Devido à I Guerra Mundial, o mandato de Venceslau Brás foi o segundo governo que mais se valeu do estado de sítio até 1930, por 401 dias, ficando atrás apenas da presidência de Artur Bernardes (1922-1926), (Gasparetto Júnior, 2018: 291). Não é possível, dentro dos limites deste trabalho, abarcar uma análise aprofundada do estado de sítio, dar conta das nuances verificadas em sua aplicação sob cada mandato do período e compreender profundamente a transformação constitucional pelo qual a medida passou. Interessa-nos, especificamente, constatar a justificativa ideológica para o emprego desse instrumento durante a Grande Guerra e de que modo ele se relaciona efetivamente com o processo de totalização da guerra. Não podemos deixar de considerar, entretanto, as tensões sociais existentes no país e na América Latina naquele período, relacionadas à crise econômica derivada do conflito, de abastecimento de alimentos, disputas do movimento operário e recrudescimento da violência contra estrangeiros (Rinke, 2017: 183 y Bisher, 2016: 79, 156-157, 200-2001, 259).

Sugerimos que dentro de um contexto de pouca vulnerabilidade externa, como foi o do Brasil entre 1914 e 1918, a retórica da ameaça do inimigo e, consequentemente, da segurança nacional foi acionada com o intuito de suprimir tais tensões que não se limitavam ao evento da guerra, e que se valeu da mesma para manter a ordem no já corroído republicanismo em voga. Não só isso, a I Guerra Mundial se colocou como palco estratégico da fundamentação e legitimação do projeto nacional. Nesse sentido, e em consonância com a interpretação de Olivier Compagnon (2014: 251), não apenas o estado de beligerância como também a decisão extraordinária de estabelecer o estado de sítio foi ao encontro de interesses nacionais que foram paulatinamente se impondo sobre dispositivos argumentativos relativos à entrada do Brasil no conflito.

13 Para o caso alemão ver Germany, Propaganda and Total War. The Sins of Omission (Welch, 2000: 4); para a França cf. "Les débuts de la Grande Guerre en France: dictature imposée du militaire ou retrait du politique" (Crochet, 2007: 2); Censorship of the Press in France 1917-1918 (Sorrie, 2014: 47) e État de siège, censure: un passage brutal à l'état de guerre (Musée de la Grande Guerre, s.d.). Já para o caso britânico e a instituição do Defence of the Realm Act (DORA) ver Cotter (1953: 384-385) e Hynes (2017). 
Desse modo, a censura que seria aplicada pelas autoridades deveria passar pelos critérios de segurança do território, bem como pela filtragem de informações militares cruciais que não poderiam correr o risco de serem interceptadas pelo inimigo. Em discurso proferido no dia 10 de novembro de 1917 no Congresso Nacional a respeito da medida, o deputado José Luiz Alves atentava que o inimigo não se resumia ao alemão, mas poderia ser interno e multiforme, e é contra esses elementos que a censura precisaria ser exercida em todo o território nacional, sobretudo no interior do país. Sua argumentação final recai sobre a obra Direito Público em tempo de guerra (1915), de Joseph Barthélémy ${ }_{1}^{14}$ citando o jurista francês:

[...] que será legitimo sacrificar essa liberdade na medida em que esse sacrifício fôr exigido pela necessidade da defesa nacional [...] nesta guerra, a attitude, a resistencia, os sentimentos da porção não armada do paiz, da porção civil, são elementos essenciaes da victoria [...] O problema da restriccão da liberdade da imprensa em tempo de guerra não é um problema de princípios, mas sómente um problema de medida (Alves, 1917: 28).

Ao analisar o processo de brutalização ocorrido na Alemanha, ${ }^{15}$ George L. Mosse atenta que o conflito inspirou um sentido de missão universal, no qual cada lado beligerante passou a desumanizar o inimigo e desejar sua capitulação incondicional. A partir dessa lógica, "o inimigo foi transformado em um antítipo, simbolizando o inverso de todos os valores que a sociedade estima" (Mosse, 1990: 174). ${ }^{16}$ O processo de estereotipação se configurou contra aqueles que diferiam das normas existentes e representavam uma ameaça social, tais como judeus e ciganos. Isso também levou, segundo o historiador alemão, ao reforço não só do estereótipo do inimigo vindo de fora, como também daquele que se encontrava dentro das fronteiras nacionais, que eram reconhecidos como um perigo à estabilidade da nação e que perturbavam a autoimagem da sociedade (Mosse, 1990: 174-175). Nesses termos, podemos dizer que não só os teuto-brasileiros, por sua associação direta com a Alemanha, poderiam se configurar como inimigo interno, mas também todos aqueles indivíduos que não se enquadravam nessa lógica, seja por critérios políticos, seja por critérios raciais. ${ }^{17}$

14 Em sua obra, Joseph Barthélémy (1915) discute, dentre outros temas, as implicações legais do estado de sítio na França. Olivier Forcade (2016: 22) a cita, juntamente com trabalhos de outros juristas, como parte do debate público em torno da instauração de censura naquele país em 1915.

15 Cabe mencionar que essa é uma das teorias interpretativas sobre a Grande Guerra, que considera o conflito como uma ruptura tanto na história europeia quanto mundial, na qual a banalização da violência do evento estaria relacionada à brutalização da política das sociedades do pós-guerra. Nessa linha se encontram os trabalhos de George L. Mosse (1990) e de seu herdeiro intelectual Modris Eksteins (1989), que compreende a guerra como um prenúncio do modernismo nas artes. A tese de Jay Winter (1990) vai em direção oposta, apontando para o retorno a uma linguagem familiar e tradicional - clássica, romântica e cristã - como forma de expressão do luto daquelas sociedades. No rescaldo das reflexões sobre rememoração estão, por exemplo, os trabalhos de Stefan Goebel (2007), Adrian Gregory (2014), Elise Julien (2010) e Sílvia Correia (2015). Como o próprio Winter salienta, tais formas de interpretar as representações do conflito não são contraditórias, pois o que elas "têm em comum é a percepção de que a Grande Guerra foi um momento no qual as representações anteriores da guerra começaram a fraturar e, finalmente, a se decompor" (Prost y Winter, 2005: 183).

16 Tradução nossa. ("The enemy transformed into the anti-type, symbolizing the reversal of all the values which society held dear").

17 No sentido político me refiro, particularmente, à questão social, relacionada ao movimento operário, e a disputas políticas internas do país, sobretudo no estado de São Paulo. No que diz respeito à 
O maior oponente no Congresso Nacional da promulgação do estado de sítio, Mauricio de Lacerda, ${ }^{18}$ acreditava que a censura era o único objetivo político do sítio que, como consequência, isolou o Governo da opinião nacional. Para o deputado fluminense, o estado de guerra por si só já garantiria as providências necessárias para a nação: a censura, a vigilância sobre os correios e telégrafos e sobre a espionagem (Anais da Câmara dos Deputados, 11 de agosto de 1918: 2211):

\begin{abstract}
O sitio conseguiu, portanto, apagar os traços da opinião nos jornaes e realizar essa maravilha em um paiz que tinha de executar na opinião a difficil tarefa de convencimento quanto a uma guerra longuinqua, por motivos que não se podem immediatamente esclarecer aos olhos do povo, porque não é guerra de aggressão no continente: conseguiu formar uma imprensa de guerra inferior á imprensa de neutralidade (Annaes da Camara dos Deputados, Sessões de 27 a 31 de dezembro de 1917, 1919: 573).
\end{abstract}

Cabe ressaltar a iniciativa de Lacerda no início da aplicação do estado de sítio para nacionalizar e proteger a imprensa brasileira de possíveis excessos do Estado. A 20 de novembro de 1917, o deputado indicou à Comissão de Constituição e Justiça da Câmara dos Deputados um projeto que deveria regular a censura no exercício da imprensa durante o estado de guerra, fosse ela interna ou externa. No entanto, seu texto se encorava em uma perspectiva de exclusão do estrangeiro residente no Brasil da participação política da produção impressa nacional. ${ }^{19}$

Para além dos elementos xenófobos presentes em seu texto, o intuito do político fluminense era limitar as prerrogativas do Poder Executivo, tendo em vista que, em suas palavras, o sítio poderia levar à tirania do Estado em um momento excepcional pelo qual o Brasil passava. Ainda segundo Mauricio de Lacerda, não existia até então qualquer lei que evitasse a supressão pelo arbítrio de todas as garantias constitucionais e até os direitos políticos, como o exercício da imprensa. A exceção seria o decreto 1.565 de 13 de outubro de 1895, expedido pelo então presidente Floriano Peixoto e seu ministro Fernando Lobo, e que teria sido aplicado pelos estados de sítios de governos sucessores, como de Prudente de Morais e Rodrigues Alves. Na realidade, o decreto foi promulgado em 1893, no qual é determinado em seu artigo $1^{\text {o }}$ a liberdade de imprensa, independente da orientação política. ${ }^{20}$

identificação de um inimigo a partir de critérios raciais, em linhas gerais, as representações dos alemães e de outros grupos étnicos na imprensa ilustrada carioca do período, tais como sírios e chineses, vinculavam características desumanizantes a essas populações, bem como apontavam para sua habilidade de se infiltrar no território brasileiro durante a guerra (Arouca, 2018: 132-133).

18 Pai do futuro governador do estado da Guanabara Carlos Lacerda, Mauricio de Lacerda integrava uma família tradicionalmente socialista e se empenhou na causa operária durante sua vida política, estimulado pela Revolução Russa. Lacerda foi deputado pelo estado de Rio de Janeiro entre 1912 e 1920 e integrou os levantes tenentistas da década de 1920. Voltou a ser deputado federal em 1930, além de apoiador da tomada de poder de Getúlio Vargas. Em 1917, suas reivindicações proletárias o fizeram participar da fundação da Liga Socialista (cf. Pechman, s.d.).

19 Para a proposta completa da lei cf. Anais da Câmara dos Deputados (23 de novembro de 1917: 4222-4224).

20 Para o decreto na íntegra cf. Decreto no 1.565. 13 de outubro de 1893. https://www2.camara.leg.br/ legin/fed/decret/1824-1899/decreto-1565-13-outubro-1893-506186-publicacaooriginal-1-pe.html 
Na prática, aconteceu como Lacerda previra e os excessos praticados pela censura começaram a emergir já no ano de 1917. Podemos sugerir que não houve, por parte do Governo Federal, um esforço em regulamentar de forma minuciosa a censura em vigor, o que levou a aplicações e interpretações incoerentes sobre o conteúdo veiculado pela imprensa - que não se limitavam a ela - e a arbitrariedades, relacionadas ou não com a guerra em curso, fato apontado pelo jornalista Medeiros e Alburquerque, ele mesmo tendo tido um artigo censurado na imprensa:

\begin{abstract}
A censura, entre nós, segue rumo diverso [da Europa]: ella está revelando ser um instrumento da politica pessoal de certos ministros. A questão essencial, da guerra, questão a qual foi instituida, pouco lhe interessa. O que lhe importa é que os ministros que a manipulam possam preparar a sua politica individual (Annaes da Camara dos Deputados, Sessões de 27 a 31 de dezembro de 1917, 1919: 662).
\end{abstract}

Ainda no que diz respeito às arbitrariedades, no interior do estado do Rio de Janeiro uma série de violências foram praticadas por autoridades locais, sob pretexto de exercitarem a fiscalização sobre artigos de imprensa e artigos de livre crítica de atos das mesmas autoridades locais, que não teriam nenhuma relação com a situação internacional. A reclamação foi levada por Mozart Lago, jornalista da capital e representante do Jornal do Commercio, ao deputado Faria Souto, que requereu um esclarecimento do Ministro da Justiça. Carlos Maximiliano informou em resposta que a censura da imprensa nos estados estava sendo feita por ordem e sob responsabilidade exclusiva dos governos regionais; o Ministério apenas havia transmitido para eles o teor das instruções aplicadas na capital federal, sem fazer injunção alguma (Anais da Câmara dos Deputados, 12 de dezembro de 1917: 49). ${ }^{22}$

Portanto, a organização brasileira incumbiu aos governos estaduais a tarefa de estabelecer o sistema de censura local, diferentemente do que ocorreu França, onde o exercício de propaganda e censura era centralizado no Bureau de la Presse. Neste país, os censores trabalhavam dentro do próprio governo, recebendo as páginas dos jornais à medida que iam sendo escritas, para serem objetos de crivo, e se comunicavam com as redações por telefone (A evolução da censura, 1918). Porém, conforme Olivier Forcade, a inscrição da censura como um dispositivo que se conectava à propaganda estava inserida menos em uma lógica de mascarar feitos militares e diplomáticos interessantes ao inimigo do que na produção de uma determinada opinião francesa a respeito do conflito. Para tanto, foi criado "um sistema de informações para mobilizar e enquadrar a opinião em uma guerra longa e total (isto é, o front está em toda e em nenhuma parte)" (Forcade, 2000: 45). Tal configuração não pode

21 No artigo em questão, de dezembro de 1917, Medeiros e Albuquerque comentou a apreensão do jornal carioca Lanterna. O texto completo por ser conferido em: Annaes da Camara dos Deputados, Sessões de 27 a 31 de dezembro de 1917, Volume XIV e Appendice (1919: 662).

22 A aplicação no estado de São Paulo se destacou por ter sido mais contundente e sistemática que a da capital no período, o que também sugere uma prática relativamente heterogênea pelo território brasileiro. 
ser integralmente transposta para o Brasil pois, dada a sua participação longe dos campos de batalha, as implicações da censura se relacionavam, para além dos interesses militares, com meandros da política nacional.

\section{Desdobramentos nacionais da censura}

Para além da censura da imprensa, existiram outras modalidades de aplicação da medida no Brasil. Como mencionado anteriormente, não é possível concebê-las de forma dissociada, uma vez que os Ministérios ao encargo de cada uma se relacionavam uns com os outros; pretendemos, assim, apontar tais divisões formais do ponto de vista nacional. Com base nos relatórios oficiais do Ministério da Viação e Obras Públicas, podemos afirmar que a censura postal começou a operar oficialmente no território brasileiro a 6 de novembro de 1917, tendo sido extinta em 25 de janeiro de 1919 para o interior do país, e completamente ao estrangeiro a 22 de setembro do mesmo ano. ${ }^{23}$ Sua execução teve início no Distrito Federal e nas capitais dos estados do Pará, Pernambuco, Bahia, São Paulo, Paraná e Rio Grande do Sul, onde funcionários trabalhariam na Repartição Geral dos Correios local (Relatório apresentado ao Presidente da Republica dos Estados Unidos do Brasil Exmo. Sr. Dr. Epitacio Pessôa pelo Ministro de Estado da Viação e Obras Públicas J. Pires do Rio, anno de 1919, 1921: 483). Não obstante a providência tomada para que fosse criada uma comissão em Santa Catarina, ela nunca foi efetivamente posta em prática. Desse modo, a correspondência do estado era enviada para ser examinada, e possivelmente censurada, no Paraná ou no Rio Grande do Sul. Podemos considerar que tal procedimento pode ter sido replicado em outros estados do Brasil que não contavam com a instituição oficial da censura em sua respectiva Administração dos Correios (A censura nos Correios, 1917; O germanismo no Seul, 1918; A censura Postal para Santa Catharina, 1918).

Para que o serviço pudesse ser posto em prática, no fim de 1917 foi aprovado o decreto 12.761, que autorizava aquele Ministério a abrir crédito de 150:000\$ para as despesas com a censura postal e telegráfica ordenada em consequência do estado de guerra com a Alemanha. Outros decretos vigorariam entre 1917 e 1919 para a sua manutenção, no qual foi gasto ao todo 271:665\$100 (Relatório apresentado ao Presidente da Republica dos Estados Unidos do Brasil pelo Ministro de Estado da Viação e Obras Públicas Dr. José Pires do Rio, anno de 1918, 1920: 214-215 y Relatório apresentado ao Presidente da Republica dos Estados Unidos do Brasil Exmo. Sr. Dr. Epitacio Pessôa pelo Ministro de Estado da Viação e Obras Públicas J. Pires do Rio, anno de 1919, 1921: 483-484).

23 De acordo com a documentação (1921: 484), os números relativos à censura postal estão divididos em três categorias: 1) Correspondências censuradas não apreendidas [cartas ordinárias (4.027.751), cartas expressas (11.974), cartas e impressos registrados (185.304), e impressos ordinários (586.613)]; 2) Correspondência apreendida [cartas ordinárias (152.423), cartas expressas (77), e cartas e impressos registrados (1.737)]; 3) Correspondências que tiveram livre trânsito [cartas e impressos (4.123.823), cartas expressas (1.502), e cartas e impressos registrados (69.063)]. 
Como regra, a correspondência diplomática oficial das legações e consulados deveria ficar livre de cortes e apreensões (Ofício do Embaixador dos Estados Unidos Edwin Morgan para Nilo Peçanha, 28 de dezembro de 1917; Ofício de Augusto Tavares de Lira a Nilo Peçanha, 5 de outubro de 1917), porém tal norma não foi totalmente cumprida. Houve reclamações por parte da Legação da Holanda por violação de suas cartas (Ofício de Nilo Peçanha a Augusto Tavares de Lira, 4 de março de 1918; Ofício de Augusto Tavares de Lira a Nilo Peçanha, 30 de março de 1918), assim como dos representantes diplomáticos da Argentina (Memorando de Nilo Peçanha a Augusto Tavares de Lira, 4 de março de 1918) e dos Estados Unidos (Ofício de Edwin Morgan a Nilo Peçanha, 28 de dezembro de 1917). Também ocorreu a apreensão de correspondência por suspeita de espionagem (Ofício confidencial de Nilo Peçanha ao Ministro Interino do Ministério da Justiça Augusto Tavares de Lira, 9 de março de 1918; Ofício do Ministro Interino da Justiça Augusto Tavares de Lira a Nilo Peçanha, 21 de março de 1918).

A censura postal, entretanto, não se limitou à correspondência de cartas (Luebke, 1987: 172), uma vez que quaisquer impressos também passavam por seu crivo. Com o estado de guerra passou a haver a proibição da publicação e distribuição desse tipo de material em língua alemã, entretanto, na prática, foi autorizada somente a livre circulação de correspondência em línguas de origem latina e inglesa. Desse modo, os Correios suspenderam o despacho e entrega de cartas e jornais vindos de determinados países aliados censurados, como, por exemplo, o órgão do Comitê Polonês de Curitiba Polak w Brazili (Ofício de Nilo Peçanha a Augusto Tavares de Lira, 7 de janeiro de 1918).

Embora tenhamos como nosso principal foco as ações por parte do Estado Brasileiro a respeito desses materiais, não podemos perder de vista o impacto cotidiano que tais medidas causaram em comunidades estrangeiras do país, sobretudo porque a cultura escrita permitia que as mesmas tivessem um maior contato com o mundo exterior. Esse foi o caso da intervenção da Legação Suíça, que solicitou a liberação de jornais em alemão de seu país para os imigrantes residentes no Brasil, tendo em vista que os periódicos já passariam pela censura francesa e britânica na Europa (Ofício de Carlos Maximiliano a Nilo Peçanha, 20 de dezembro de 1917; Ofício de Nilo Peçanha a Augusto Tavares de Lira, 7 de janeiro de 1918). Além disso, as autoridades brasileiras reconheciam a dificuldade em censurar línguas que não compreendiam (Ofício de Nilo Peçanha a Carlos Maximiliano, 31 de julho de 1918).

No que se refere ainda aos poloneses residentes do Paraná, por exemplo, foi estimado que 200 mil pessoas não poderiam receber notícias de sua terra natal (Ofício de Nilo Peçanha a Augusto Tavares de Lira, 7 de janeiro de 1918). Jornais dessa comunidade também foram proibidos, levando a uma intervenção por parte da França, que considerava a Polônia nação amiga (Ofício do Ministra da França no Brasil Paul Claudel a Nilo Peçanha, 8 de janeiro de 1918). ${ }^{24}$ Como resolução, ficou estabelecido que jornais pró Aliados deveriam 
ser uma exceção na interdição de publicação, como foi o caso do anteriormente mencionado Polak $w$ Brazili, dirigido por Casimiro Warchałowski, representante do Comitê Nacional Polonês de Paris, e reconhecido pelos Aliados como a expressão da nacionalidade polonesa.

As consequências do estado de guerra brasileiro causaram transtornos na vida econômica e privada desses grupos (A censura postal, 1917). Frederick Luebke aponta para o impacto direto e imediato que a suspensão de publicações em língua alemã teve na vida diária de teuto-brasileiros do sul do país:

\begin{abstract}
A imprensa étnica era o seu meio básico de comunicação intragrupo. Ela era também o seu principal contato com o mundo da sociedade luso-brasileira, e a forma pela qual eles descobriam o que o governo exigia ou esperava deles. Contudo, a proibição foi total. Ela foi aplicada não só aos jornais, mas a todos os periódicos, jornais de agricultores, revistas paroquiais, almanaques, literatura devocional, até mesmo traduções alemãs de clássicos da literatura portuguesa e brasileira, e livros didáticos de todos os tipos, incluindo textos para ensinar português a crianças falantes de alemão (1987: 175). ${ }^{25}$
\end{abstract}

De acordo com Luebke, para as classes dominantes brasileiras, impor o aprendizado da língua portuguesa era uma das formas pelas quais os alemães e seus descendentes poderiam finalmente se assimilar no Brasil. Tais formulações não despontaram em 1917; a Grande Guerra representou um ponto de inflexão no que diz respeito os postulados de intelectuais e políticos no período da Primeira República, que se empenhavam na construção do regime republicano e da identidade nacional desde a virada do século XIX. ${ }^{26} \mathrm{Em}$ trabalho intitulado $O$ alemanismo e o perigo alemão na literatura brasileira da primeira metade do século $X X$, Olgario Vogt afirma que, para intelectuais e homens do governo brasileiro do período, os teuto-brasileiros colocariam em risco a integridade nacional, que não comportava duplos pertencimentos (2007: 226). Logo, a guerra colocava em evidência debates, negociações identitárias e políticas de estado em relação a esse grupo étnico no território brasileiro.

Ainda no que se refere à censura postal, embora os relatórios ministeriais indiquem o fim da medida no âmbito doméstico em janeiro, de forma extra oficial ela continuou a vigorar. Um mês após o armistício, em dezembro de 1918, o jornal carioca A Noite protestava que, apesar do fim da guerra e da

região que hoje se denomina Polônia colapsaram, possibilitando sua independência. Em 1917, foi criado o Exército Polonês (ou o Exército Azul) na França que, por considerar a questão polonesa um problema interno russo, permitiu que sua criação se desse exclusivamente dentro da Légion étrangère (cf. Centek, 2014).

25 Tradução nossa. ("The ethnic press was their basic means of intragroup communication. It also was their chief contact with the world of Luso-Brazilian society, and their way of finding out what the government required or expected of them. Yet the prohibition was total. It applied not only to newspapers but to all periodicals, farm journals, church magazines, almanacs, devotional literature, even German translations of classic Portuguese and Brazilian literature, and school books of every kind, including texts for teaching Portuguese to German-speaking children").

26 Um dos expoentes dessa ideia foi o crítico literário Sílvio Romero. Em sua opinião, os alemães não eram passíveis de assimilação devido à diferença cultural e racial existente entre estes e os brasileiros. Apartados do restante do país e prósperos economicamente, eventualmente buscariam a independência política. O alemanismo e o "perigo alemão" apareceram ainda em obras de autores como Graça Aranha, Vianna Moog e Bayard Mércio (Pires, 2013: 125). 
censura postal e telegráfica já ter acabado em outros países beligerantes, no Brasil ela continuava com o mesmo rigor. 0 periódico acreditava que as gratificações recebidas pelos funcionários eram o motivo para a medida não ter sido descontinuada (A Noite, 1918). Em maio de 1919, na mesma publicação, Medeiros e Albuquerque desaprovava a censura em curso. Naquele momento, conforme o jornalista, o uso de endereços telegráficos era somente permitido para os Estados Unidos, que desde abril havia declarado que não censurava mais os cabogramas com a América Central e do Sul:

A censura entre nós [...] começou por ser estabelecida para a correspondencia mandada de uns para outros pontos do territorio nacional. $E$ isso não se fez em nenhuma outra nação. Durante todo o tempo de guerra, a França e a Italia, onde a guerra reinava furiosamente, não sentiram necessidade alguma de impôr aquele vexame aos seus cidadãos. A censura nesses paizes só se estabeleceu para as cartas que iam para ou vinham da zona de guerra (A censura, 1919).

A afirmação de Medeiros e Albuquerque é contestável. De acordo com Eberhard Demm, a censura postal foi introduzida em todos os exércitos durante a I Guerra Mundial, buscando revelar segredos militares, testar o moral dos soldados e encontrar "ideias subversivas". A medida foi estendida à correspondência da população civil, porém aplicada em diferentes graus naqueles países. Em 1918, a Grã-Bretanha contava com 5.000 censores para esse fim e, devido ao controle de todos os navios em trânsito pelo bloqueio inglês, abria as cartas e pacotes enviados entre o país e a América Latina. Nos Estados Unidos, a censura também foi instituída de forma ampla: em outubro de 1918, 180 censores controlavam por semana $77 \%$ da correspondência, deixando $20 \%$ para ser analisada na semana seguinte. Todas as comunicações interceptadas eram enviadas para a inteligência militar com sede em Washington, sede do Committee on Public Information, o departamento oficial de propaganda dos Estados Unidos. Em comparação com os norte-americanos, a censura postal alemã e francesa era mais modesta, mas ainda assim existente. ${ }^{28}$

Em última análise, importa perceber que a censura postal foi ampla no Brasil e esteve em vigor para além do fim do estado de sítio. Salientamos ainda que sua execução ganhou contornos internacionais com o auxílio da Grã-Bretanha e dos Estados Unidos, que se propuseram tanto a avaliar a metodologia empregada pelos funcionários brasileiros quanto a sugerir uma centralização da censura nacional para sua maior eficiência. Tal fato se relacionava com seus respectivos projetos de propaganda e censura durante a guerra.

A censura telegráfica, por sua vez, passou a ser executada com o fim das relações diplomáticas entre o Brasil e a Alemanha, em abril de 1917, e foi empreendida pelo Telégrafo Nacional e pelas companhias estrangeiras

27 Em janeiro, O Paiz lançava nota com a mesma reclamação (A censura postal, 1919).

28 Sobre a censura postal tanto de natureza militar quanto civil durante a Grande Guerra cf. Censorship and Propaganda in World War I: A Comprehensive History (Demm, 2019: 13-15). Detalhes sobre a correspondência francesa em "France" (Smith, 2010: 421). 
fiscalizadas pelo Governo Brasileiro. Sua aplicação passou a ser mais rigorosa com o estado de guerra, seis meses depois. No entanto, embora medidas específicas tenham sido adotadas a fim de assegurar a natureza das informações transmitidas pelo telégrafo durante a I Guerra Mundial, sobretudo na estação de Pernambuco, esse meio de comunicação já apresentava restrições em tempos de paz (Censura telegraphica, 1917).

Era lícito para países participantes da União Telegráfica Internacional sustar, mesmo sem o estado de guerra em vigor, qualquer telegrama particular que fosse julgado perigoso à "segurança do Estado, às leis, à ordem pública e à

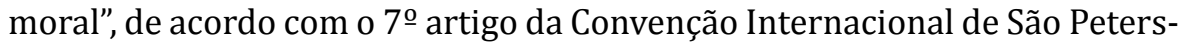
burgo. ${ }^{29}$ Com o dilatamento da censura, foi proibida aceitação de telegramas em códigos particulares e com linguagem cifrada, bem como em idiomas que não o português, francês, inglês, espanhol e italiano. Também foi permitido o uso do código universal, mediante essas restrições.

Por fim, tendo como referência este período, pudemos rastrear o emprego da censura telefônica. Técnica, industrial e administrativamente, os serviços telegráficos e telefônicos eram reconhecidos pelo Governo Brasileiro como universalmente idênticos aos do telegrama. Sendo assim, a estes seriam aplicáveis as disposições do regimento internacional, o que justificaria a censura no serviço telefônico em qualquer tempo e circunstância. Tendo em vista que as comunicações telefônicas não deixavam originais, registro ou vestígios de qualquer espécie, o Governo Federal assumia que, durante a Grande Guerra, essa censura exigia maior "perspicácia, atenção e devotamento" que a exercida pelo telégrafo, correios e imprensa (Anais da Câmara dos Deputados, 8 de dezembro de 1917: 4685).

A alçada da fiscalização do serviço telefônico ficou sob responsabilidade do Ministério da Guerra, entretanto, originalmente, a administração geral cabia ao Ministério da Viação e Obras Públicas. Para tanto, o Congresso Nacional decretou a 8 de dezembro de 1917 que a companhia Brasilianische Elektricitäts Gesellschaft ${ }^{30}$ deveria repassar para o Governo Federal os edifícios, as redes de cabo e linhas, as instalações, e o estoque de material em depósito relacionado ao serviço telefônico. ${ }^{31}$

29 A Conferência Telegráfica Internacional foi celebrada em 1875 em São Petersburgo entre 15 países europeus e a Pérsia, com base na Convenção de Paris, de 1864, que tinha como objetivo estabelecer um cabo telegráfico transatlântico unindo a Europa à América. O Brasil só iria aderi-la em 1877 (Almeida, 1997: 85). O acordo de 1875 está disponível integralmente (em francês) em http://handle.itu. int/11.1004/020.1000/4.4.

30 A empresa Brasilianische Elektricitäts Gesellschaft havia sido adquirida em 1905 pela companhia Rio Light, de capital americano, por meio da formação da Rio de Janeiro Telephone Company. Além das comunicações telefônicas, o grupo alemão Siemens \& Halske Aktien Gesellschaft também controlava parte do transporte sobre trilhos da cidade do Rio de Janeiro. Para um levantamento das empresas que tinham concessão no Brasil entre os séculos XIX e XX cf. A expansão da Rio de Janeiro Tramway Light and Power ou as origens do "Polvo Canadense" (von der Weid, 2003).

31 Para todos os artigos do decreto cf. Anais da Câmara dos Deputados (8 de dezembro de 1917: 27). 
Conforme Matías Molina, a Western and Brazilian Telegraph Company instalou em 1877 o primeiro aparelho de telefone do Brasil e, com o seu capital, foi formada dois anos depois a Companhia Telephonica do Brasil. Em 1880, a Repartição Geral de Telégrafos passou a administrar o serviço, mas em pouco tempo concedeu a sua exploração para o capital estrangeiro, que operou no país durante quase um século. Na cidade de São Paulo, a Companhia Rede Telephonica Bragantina instalou entre 1896 e 1915 uma rede de $1600 \mathrm{~km}$ de linha, a maior do país até então (Molina, 2015). Foi a partir dessa estrutura que, em dezembro de 1917, a Delegacia Geral tomou providências no sentido de ser executada a censura do serviço de telefones da Companhia Telefônica de São Paulo e da Rede Telefônica Bragantina (A censura telephonica, 1917), o que indica que o Ministério da Justiça também tinha certo grau de responsabilidade sobre a aplicação da medida. Desse modo, tal como ocorreu com as outras modalidades de censura, o controle telefônico perpassava por mais de um ministério.

\section{Considerações Finais}

Buscamos responder com o presente artigo como parte da organização de censura dos Aliados foi estruturada e como tais modelos, que variaram de país para país, impactaram a forma como foi veiculado o conteúdo a respeito da I Guerra Mundial no Brasil. Se, em um primeiro momento, a França detinha um maior controle das notícias, sobretudo porque o seu Governo estava associado à agência Havas, a partir de 1917 os Estados Unidos puderam se vincular a esse poderio midiático, assim como progressivamente foram instaurando sua política de propaganda ao redor do mundo em aliança com as agências de seu país, sobretudo por meio da Associated Press. O Brasil, por sua vez, delimitou diretrizes nacionais de censura com a instauração do estado de guerra e o estado de sítio, que foram executadas por diversos ministérios de forma integrada.

Nos termos apresentados acima, a censura brasileira aplicada durante a I Guerra Mundial teria excedido a caracterização basilar do procedimento de censura de guerra, a saber, o de prevenir que o inimigo interceptasse informações sensíveis e reforçar o moral de seus cidadãos e soldados (Welch, 2003: 70). Entretanto, o cerceamento de opiniões e informações referentes à política nacional se entrelaçavam com o fato de que o Brasil efetivamente havia entrado no conflito e passou a tomar medidas relativas à segurança de seu território, embora não houvesse perigo imediato de ameaça estrangeira. Ainda assim, existia no país uma germanofobia cultivada desde a virada do século XIX, que encontrou em 1917 o seu ponto exponencial, ecoando nos discursos relativos ao conflito e à segurança nacional (cf. Vogt, 2007). David Welch nos esclarece que a Grande Guerra 
maioria das nações as considerava vital, do ponto de vista da segurança nacional, para controlar os meios de comunicações. De todos os meios disponíveis, nenhum era mais levado em consideração do que a imprensa (2003: 70).

Embora tenha havido contendas públicas - seja na imprensa, seja no Congresso Nacional - relativas às atribuições da censura em suas diversas modalidades, não podemos perder de vista que estes eram elementos discursivos que serviam para legitimar o cerceamento dos espaços democráticos durante a guerra e interesses particulares, além de procurar direcionar a opinião pública. A instauração do sítio abriu uma prerrogativa para um mecanismo de repressão que, em sua aplicação, tinha um controle a nível estadual difuso.

Partindo da ideia de que o Brasil — bem como a América Latina de forma ampla - deve ser enquadrado dentro de uma perspectiva que considera a I Guerra Mundial como uma guerra global, importa percebermos como o desenvolvimento de tal prática no país se relaciona de uma forma ampla com a estrutura inaugurada pela Grande Guerra a respeito da batalha de propaganda pelos "corações e mentes" latino-americanos, que não foi linear e tampouco se manifestou da mesma forma na região.

32 Tradução nossa. (“...] was the first modern war in which all the belligerents deployed the twin weapons of censorship and propaganda to rigidly control public opinion. Most nations considered it vital, from the point of view of national security, to control the means of communication. Of all the means available, none was more highly regarded than the press"). 


\section{Q Bibliografia}

" Abranches, D. (1915). A conflagração europeia e suas causas: Discurso proferido na Câmara dos Deputados ao Congresso Nacional do Brasil em 26 de setembro de 1914. Almeida Marques \& C.

" A censura. (22 de maio de 1919). A Noite.

"A censura na imprensa. (31 de outubro de 1917). Correio Paulistano.

"A censura nos Correios. (9 de novembro de 1917). O Dia.

" A censura postal. (5 de janeiro de 1919). O Paiz.

" A censura postal. (5 de novembro de 1917). A Noite.

"A censura telephonica. (30 de dezembro de 1917). O Imparcial.

" A evolução da censura. (18 de junho de 1918). Correio da Manhã.

"A censura postal para Santa Catharina. (9 de agosto de 1918). O Dia.

" Almeida, C. R. (2017). A Grande Guerra (1914-1918) e os Boletins Semanais de Júlio Mesquita [Dissertação de Mestrado, Universidade Estadual Paulista].

" Anais da Câmara dos Deputados. (11 de agosto de 1918). Congresso Nacional (Brasil).

" Anais da Câmara dos Deputados. (8 de dezembro de 1917). Congresso Nacional (Brasil).

" Anais da Câmara dos Deputados. (12 de dezembro de 1917). Congresso Nacional (Brasil).

" Anais da Câmara dos Deputados. (27-31 de dezembro de 1917). Congresso Nacional (Brasil).

" Anais da Câmara dos Deputados. (23 de novembro de 1917). Congresso Nacional (Brasil).

" Almeida, P. R. (1997). A democratização da sociedade internacional e o Brasil: ensaio sobre uma mutação histórica de longo prazo (1815-1997). Revista Brasileira de Política Internacional, 40(2).

" Alves, J. L. (1917). O Estado de Sítio e o Estado de Guerra. Imprensa Nacional.

"Arouca, F. B. (2018). As representações da Primeira Guerra Mundial em O Malho (19141918) [Dissertação de Mestrado, Universidade Federal do Rio de Janeiro].

" Audoin-Rouzeau, S y Becker, A. (1998). Violência e consentimento: a "cultura de guerra" do primeiro conflito mundial en J-P. Rioux y J-F. Sirinelli (ed.), Por uma nova história cultural. Estampa.

" Barthélemy, J. (1915). Le Droit public en temps de guerre. Giard \& Brière.

" Biondi, L. (2009). A Greve Geral em São Paulo e a Imigração Italiana: Novas Perspectivas. Cadernos AEL: Imigração, 15(27).

" Bisher, J. (2016). The Intelligence War in Latin America, 1914-1922. McFarland \& Company.

"Brum, C. E. (2018). A (des)mobilização de médicos na Grande Guerra: o caso da Missão Médica Brasileira na França (1918-1919) [Tese de Doutorado, Pontifícia Universidade Católica do Rio Grande do Sul].

"Carvalho, J. M. (1990). A Formação das Almas: O imaginário da República no Brasil. Companhia das Letras. 
"Censura de imprensa. (28 de outubro de 1917). O Paiz.

" Censura telegraphica. (31 de outubro de 1917). Diário de Pernambuco.

"Centek, J. (8 de outubro de 2014). Polish Army in France en 1914-1918-online. International Encyclopedia of the First World War, https://encyclopedia.1914-1918online.net/article/polish_army_in_france

"Claro Pires, L. (2013). Intelectuais nas trincheiras: a Liga Brasileira pelos Aliados e o debate sobre a Primeira Guerra Mundial (1914-1919) [Dissertação de Mestrado, Universidade Estadual do Rio de Janeiro].

"Compagnon, O. (2014). O Adeus à Europa: A América Latina e a Grande Guerra. Rocco.

" Compagnon, O. et al. (dir.). (2018). La Gran Guerra en América Latina: una historia conectada. CEMCA.

" Complete Report of the Chairman of the Committee on Public Information, 1917:1918:1919. (1920). Government Publishing Office.

" Constituição da República dos Estados Unidos do Brasil. 24 de fevereiro de 1891 (Brasil).

"Correia, S. (2015). Entre heróis e mortos, políticas da memória da Primeira Guerra Mundial em Portugal (1918-1933). 7 Letras.

" Cotter, C. P. (1953). Constitutionalizing Emergency Powers: The British Experience. Stanford Law Review, 5(3).

" Crochet, F. (2007). Les débuts de la Grande Guerre en France: dictature imposée du militaire ou retrait du politique. Revue historique des armées, 248.

" Darnton, R. (2016). Censores em ação: Como os Estados influenciaram a literatura. Companhia das Letras.

"Daróz, C. (2016). O Brasil na Primeira Guerra Mundial. Contexto.

" Decreto no 1.565 de 1893 [Vice-Presidente da Republica dos Estados Unidos do Brazil]. 13 de outubro de 1893. https://www2.camara.leg.br/legin/fed/decret/1824-1899/decreto1565-13-outubro-1893-506186-publicacaooriginal-1-pe.html

" Demm, E. (2019). Censorship and Propaganda in World War I: A Comprehensive History. Bloomsbury Academic.

"Djebabla, M. (2014). "Fight the Huns with food": mobilizing Canadian civilians for the food war effort during the Great War, 1914-1918 en T. Paddock (ed.), World War I and Propaganda. Brill.

" Dos Santos, K. W. (2016). Paz entre nós, guerra aos senhores. O internacionalismo anarquista e as articulações políticas e sindicais nos grupos e periódicos anarquistas Guerra Sociale e A Plebe na segunda década do século XX em São Paulo [Dissertação de Mestrado, Universidade Federal de São Paulo].

" Eksteins, M. (1989). Rites of Spring: The Great War and the Birth of the Modern Age. Houghton.

"Enders, A. y Compagnon, O. (2004). L’Amérique latine et la guerre en S. Audoin-Rouzeau, S. y J-J. Becker (ed.), Encyclopédie de la Grande Guerre, 1914-1918. Bayard.

"État de siège, censure: un passage brutal à l'état de guerre. (20 de maio de 2020). Musée de la Grande Guerre. https://www.museedelagrandeguerre.eu/fr/espace-pedagogique/ dossiers-documentaires/mobilisation/etat-de-siege.html

" Fausto, B. (1977). Trabalho urbano e Conflito social: 1890-1920. Difel.

"Forcade, O. (2000). Censure, secret et opinion en France de 1914 à 1919. Matériaux pour 
I'histoire de notre temps, 58.

" Forcade, O. (2016). La Censure en France pendant la Grande Guerre. Fayard.

" Garambone, S. (2003). A Primeira Guerra Mundial e a Imprensa Brasileira. Mauad.

"Gasparetto Júnior, A. (2018). Recursos extremos da administração estatal: as declarações de estado de sítio na Primeira República Brasileira [Tese de Doutorado, Universidade Federal de Juiz de Fora].

" Goebel, S. (2007). The Great War and Medieval Memory War, Remembrance and Medievalism in Britain and Germany, 1914-1940. Cambridge University Press.

" Gregory, A. (2014). The Last Great War. British Society and the First World War. Cambridge University Press.

" Horne, J. (dir.). (2010). A Companion to World War I. Oxford University Press.

" Horne, J. (1997). Remobilizing for 'total war': France and Britain, 1917-1918 en J. Horne (ed.), State, society and mobilization: in Europe during the First World War. Cambridge University Press.

" Hynes, G. (10 de outubro de 2017). Defence of the Realm Act (DORA) en 1914-1918-online. International Encyclopedia of the First World War. https:// encyclopedia.1914-1918-online.net/article/defence_of_the_realm_act_dora

"Instruções aos correspondentes dos jornaes. (28 de outubro de 1917). O Paiz.

" Julien, E. (2010). Paris, Berlin: La mémoire de la guerre 1914-1933. Presses universitaires de Rennes.

" Lopreato, C. R. (1996). O Espírito da Revolta: a greve geral anarquista de 1917 [Tese de Doutorado, Universidade Estadual de Campinas].

" Luebke, F. C. (1987). Germans in Brazil: A Comparative History of Cultural Conflict During World War I. Louisiana State University Press.

" McGee Deutsch, S. (1999). Las Derechas: The Extreme Right in Argentina, Brazil, and Chile, 1890- 1939. Stanford University Press.

" Memorando de Nilo Peçanha a Augusto Tavares de Lira. (4 de março de 1918). Arquivo Histórico do Itamaraty, 305-2-15.

" Molina, M. (2015). A História dos Jornais no Brasil. Companhia das Letras.

" Mosse, G. (1990). Fallen Soldiers: Reshaping the Memory of the World Wars. Oxford University Press.

" Müller, B. (2004). Censorship and Cultural Regulation: Mapping the Territory en B. Müller (ed.), Censorship and Cultural Regulation in the Modern Age (Critical Studies 22). Rodopi.

" O Brasil em guerra. (30 de outubro de 1917). O Paiz.

" Ofício confidencial de Nilo Peçanha ao Ministro Interino do Ministério da Justiça Augusto Tavares de Lira. (9 de março de 1918). Arquivo Histórico do Itamaraty, 303-1-4.

" Ofício de Augusto Tavares de Lira a Nilo Peçanha. (30 de março de 1918). Arquivo Histórico do Itamaraty, 305-1-11.

" Ofício de Augusto Tavares de Lira a Nilo Peçanha. (5 de outubro de 1917). Arquivo Histórico do Itamaraty, 305-1-11.

" Ofício de Carlos Maximiliano a Nilo Peçanha. (20 de dezembro de 1917). Arquivo Histórico do Itamaraty, 301-4-14.

" Ofício de Nilo Peçanha a Augusto Tavares de Lira. (4 de março de 1918). Arquivo Histórico 
do Itamaraty, 305-2-15.

" Ofício de Nilo Peçanha a Augusto Tavares de Lira. (7 de janeiro de 1918). Arquivo Histórico do Itamaraty, 305-2-15.

" Ofício de Nilo Peçanha a Carlos Maximiliano. (31 de julho de 1918). Arquivo Histórico do Itamaraty, 303-1-4.

" Ofício do Embaixador dos Estados Unidos Edwin Morgan para Nilo Peçanha. (28 de dezembro de 1917). Arquivo Histórico do Itamaraty, 280-2-13.

" Ofício do Ministério da Justiça e Negócios Interiores ao Itamaraty. (17 de setembro de 1918). Arquivo Histórico do Itamaraty, 301-4-14.

" Ofício do Ministro da França no Brasil Paul Claudel a Nilo Peçanha. (8 de janeiro de 1918). Arquivo Histórico do Itamaraty, 283-4-15.

" Ofício do Ministro Interino da Justiça Augusto Tavares de Lira a Nilo Peçanha. (21 de março de 1918). Arquivo Histórico do Itamaraty, 301-4-14.

" O germanismo no Sul. (11 de fevereiro de 1918). A Noite.

" Paddock, T. (2014). Introduction en T. Paddock (ed.), World War I and Propaganda. Brill.

"Pechman, R. (s.d.). Maurício de Lacerda. CPDOC. http://www.fgv.br/cpdoc/acervo/ dicionarios/verbete- biografico/mauricio-paiva-de-lacerda.

" Pennell, C. (2014). Presenting the war in Ireland en T. Paddock (ed.), World War I and Propaganda. Brill.

" Prost, A. y Winter, J. (2005). The Great War in History: Debates and Controversies, 1914 to the Present. Cambridge University Press.

" Rasmussen, A. (2010). Science and Technology en J. Horne (ed.), A Companion to World War I. Oxford University Press.

" Relatório apresentado ao Presidente da Republica dos Estados Unidos do Brasil Exmo. Sr. Dr. Epitacio Pessôa pelo Ministro de Estado da Viação e Obras Públicas J. Pires do Rio, anno de 1919. (1921). Imprensa Nacional. Ministério da Viação e Obras Públicas (Brasil).

" Relatórios apresentado ao Presidente da Republica dos Estados Unidos do Brasil pelo Ministro da Justiça e Negócios Interiores Dr. Carlos Maximiliano Pereira dos Santos dos anos de 1917 e 1918 (1918). Imprensa Nacional. Ministério da Justiça e Negócios Interiores (Brasil).

" Relatório apresentado ao Presidente da Republica dos Estados Unidos do Brasil pelo Ministro de Estado da Viação e Obras Públicas Dr. José Pires do Rio, anno de 1918 (1920). Imprensa Nacional. Ministério da Viação e Obras Públicas (Brasil).

" Rinke, S. (2017). Latin America and the First World War. Cambridge University Press.

" Rinke, S. (2015). Propaganda War (Latin America) en 1914-1918 online. International Encyclopedia of the First World War. https://encyclopedia.1914-1918-online.net/article/ propaganda_war_latin_america

" Robertson, E. (2014). Propaganda and manufactured hatred: A reappraisal of the ethics of First World War British and Australian atrocity propaganda. Public Relations Inquiry, 3(2).

" Rosenberg, E. S. (2010). The U.S. Government and the Communications Revolution during World War I en A. K. Frank y K. Osgood (ed.), Selling war in a media age: the presidency and public opinion in the American. University Press of Florida.

" Sanders, M. y Taylor, P. M. (1982). British Propaganda during the First World War, 191418. The MacMillan Press. 
"Smith, L. V. (2010). France en J. Horne (ed.), A Companion to World War I. Oxford University Press.

" Sorrie, C. (2014). Censorship of the Press in France 1917-1918 [Tese de Doutorado, London School of Economics and Political Science].

"Steuer, K. (2014). German Propaganda and Prisoners-of-War during World War I en T. Paddock (ed.), World War I and Propaganda. Brill.

" Tato, M. I. (2017). La trinchera austral. La sociedad argentina ante la Primera Guerra Mundial. Prohistoria Ediciones.

" Tato, M. I. (2014). Luring Neutrals. Allied and German Propaganda in Argentina during the First World War en T. Paddock (ed.), World War I and Propaganda. Brill.

"Vinhosa, F. L. (2015). O Brasil e a Primeira Guerra Mundial: a diplomacia brasileira e as grandes potências. IHGB.

"Vogt, O. P. (2007). O alemanismo e o perigo alemão na literatura brasileira da primeira metade do século XX. Signo, 32(53).

"Von der Weid, E. (2003). A expansão da Rio de Janeiro Tramway Light and Power ou as origens do "Polvo Canadense". Fundação Casa de Rui Barbosa.

"Welch, D. (2003). Censorship en N. J. Cull et al. (ed), Propaganda and Mass Persuasion: Historical Encyclopedia, 1500 to the Present. ABC Clio.

"Welch, D. (2000). Germany, Propaganda and Total War. The Sins of Omission. Rutgers University Press.

"Winter, J. (2014a). General Introduction en J. Winter (ed.), The Cambridge History of the First World War. (Vol. 1). Cambridge University Press.

"Winter, J. (1998). Propaganda and the Mobilization of Consent en H. Strachan (ed.), The Oxford Illustrated History of the First World War. Oxford University Press.

"Winter, J. (2014b). The transnational history of the First World War. Teaching History, 156.

\section{Sobre o autor}

Fernanda Bana Arouca é Mestre em História Social pelo Programa de Pós-Graduação em História Social da Universidade Federal do Rio de Janeiro (PPGHIS-UFRJ), atualmente doutoranda na mesma instituição e bolsista CAPES. Pesquisa representações, propaganda e censura da Primeira Guerra Mundial.

(D)http://orcid.com/0000-0002-2491-4742

\section{Sobre la autora}

Fernanda Bana Arouca es Magíster en Historia Social por el Programa de Posgrado en Historia Social de la Universidad Federal de Río de Janeiro (PPGHIS-UFRJ) y actualmente es doctoranda en la misma institución y becaria CAPES. Investiga las representaciones, la propaganda y la censura en la Primera Guerra Mundial. 


\section{About the author}

Fernanda Bana Arouca holds a Master's Degree in Social History from the Postgraduate Program at the Federal University of Rio de Janeiro (PPGHIS-UFRJ). She is currently a PhD candidate at the same institution and a CAPES fellow. She researches representations, propaganda, and censorship during World War I. 